\title{
Rhodium Adsorption on Gallic Acid Resol Resin
}

\author{
M. $\mathrm{CAN}^{*}$ \\ Vocational School of Arifiye, 54580, Sakarya University, Turkey
}

\begin{abstract}
A new adsorbent resin has been developed by immobilizing gallic acid with formaldehyde, and its adsorption properties to $\mathrm{Rh}^{3+}$ were reviewed with respect to the collection in aqueous solution. Linear and nonlinear regression procedures have been applied to the Langmuir, Freundlich, Tempkin, Dubinin-Radushkevich, and Redlich-Peterson isotherms. The resin exhibited good adsorption capacity towards $\mathrm{Rh}^{3+}$ from acidic aqueous solutions $\left(\left[\mathrm{H}^{+}\right]=1 \mathrm{M}\right.$, $\left.\left[\mathrm{Cl}^{-}\right]=1 \mathrm{M}\right)$. The equilibrium adsorption capacity at $293 \mathrm{~K}$ was up to $69.43 \mathrm{mg} \mathrm{g}^{-1}$. The adsorption isotherms could be well described by Langmiur equation. The experimental studies suggested that gallic acid formaldehyde resin was effective for the adsorption of $\mathrm{Rh}^{3+}$ from chloride acid solutions, and the loaded $\mathrm{Rh}^{3+}$ could be easily desorbed from the $1 \mathrm{M} \mathrm{HNO}_{3}+0.1 \mathrm{M} \mathrm{NaClO}_{3}$ solution mixture with a hundred percent efficiency. Thermodynamic parameters such as the entropy change, enthalpy change and Gibbs free energy change were calculated. The adsorption of $\mathrm{Rh}^{3+}$ was found to be an endothermic adsorption process. This suggested that the resin can be used as an active biosorbent for the recovery of $\mathrm{Rh}^{3+}$ from $1 \mathrm{M} \mathrm{HCl}$ concentrated acid solution.
\end{abstract}

DOI: 10.12693/APhysPolA.127.1301

PACS: $82.30 . \mathrm{Hk}$

\section{Introduction}

Because of lower ore reserve and many different industrial applications, Platinum Group Metals (PGM) must be recycled. Rhodium is one of the most expensive PGM. Adsorption of rhodium (III) from chlorine and other ligand-containing aqueous solutions has been studied by several methods. Over the years, interest has been shifted toward developing separation agents from a variety of low-cost biomaterials, used as starting materials, such as cellulosic materials [1], chitosan [2], tannin materials $[3,4]$, etc. for precious metals separation. The main advantages of using bioderived materials as adsorbents are the unlimited supply of feed materials, no production of secondary compounds such as sludge, biodegradability, and environmentally friendly nature [5].

In our previous paper [6], we reported the successfull synthesis and characterization of insoluble tannin polymer particles, however adsorption isotherm, thermodynamic and elution experiments have not been performed. In this work, the adsorption behavior of gallic acid resol polymer (GAR) of $\mathrm{Rh}$ (III) ions in model solutions, in strongly acidic conditions was investigated batchwise. For this purpose, the effects of particle size and dose of sawdust, $\mathrm{pH}$, contact time and of the initial Rh (III) concentration were investigated. The Langmuir, Freundlich, Temkin, Dubinin-Radushkevich (D-R), and Redlich-Peterson (R-P) isotherms were used to fit the equilibrium data. This paper the thermodynamic parameters such as Gibbs free energy change $\left(\Delta G^{\circ}\right)$, enthalpy change $\left(\Delta H^{\circ}\right)$ and entropy change $\left(\Delta S^{\circ}\right)$ have been calculated and discussed. Langmuir and R-P constants of experimental data were calculated with nonlinear regression method using Microsoft Excel's Solver Extension

*e-mail: mstacan@gmail.com software program. Chi-square test was used to evaluate the models which have best fit with experimental data. In addition, different stripping solutions were also investigated for elution of adsorbed Rh (III) ion from GAR particle surface.

\section{Experimental}

\subsection{Materials}

Gallic acid was purchased from Alfa Aesar GmbH\&Co. $\mathrm{RhCl}_{3} \cdot 3 \mathrm{H}_{2} \mathrm{O}, \mathrm{NH}_{3}, \mathrm{HCOH}, \mathrm{HNO}_{3}, \mathrm{HCl}, \mathrm{NaCl}$ and $\mathrm{NaOH}$ were purchased from Merck Company. AAS standard solutions for determination of PGM were purchased form UltraScientific Company. All other reagents were analytical grade. The aqueous $\mathrm{Rh}$ (III) stock solution was prepared from solid $\mathrm{RhCl}_{3} \cdot 3 \mathrm{H}_{2} \mathrm{O}$ in $1.0 \mathrm{M} \mathrm{HCl}$. The studied solutions of $\mathrm{Rh}$ (III) were obtained by dilution with $\mathrm{NaOH}$ or $\mathrm{HNO}_{3}$ to adjust the $\mathrm{H}^{+}$concentration to the desired value. The Rh (III) solutions were prepared by dilution with ultra-pure water (Milli-Q, UK). Moreover, a suitable chloride concentration was obtained by adding $\mathrm{HNO}_{3}$ and $\mathrm{NaCl}$ solution. Preparation of GAR polymer was explained in detail at our recent publication dealing with the synthesis and characterization of the polymer [6].

\subsection{Adsorption studies}

The rhodium (III) solution was prepared by diluting stock solutions to concentrations of mainly $50 \mathrm{mg} / \mathrm{l}$. $50 \mathrm{ml}$ of metal ion solutions prepared for adsorption experiments were stirred after adding $200 \mathrm{mg}$ of GAR particles. All adsorption experiments were carried out in standard conditions and strictly adhered to batchwise system. Only adsorption capacity experiments were carried out by agitating $1 \mathrm{~g}$ of GAR with $1000 \mathrm{ml}$ of metal solution, with the various initial metal concentrations, for $150 \mathrm{~min}$ (the time required for equilibrium to be reached between metal ions adsorbed and metal ions in solution). The experiments were performed at $300 \mathrm{rpm}$. The initial pHs of 
the solutions were controlled by adding a small amount of $\mathrm{HCl}, \mathrm{HNO}_{3}, \mathrm{NaOH}$ and $\mathrm{HClO}_{4}$. At the end of the adsorption period, $15 \mathrm{ml}$ samples were centrifuged and the solutions were filtered through a $0.45 \mu \mathrm{m}$ Milipore filter paper to avoid any solid particle in the aqueous phase. Samples were measured using AAS. All the adsorption tests were performed at least twice so as to avoid wrong interpretation, owing to any experimental errors. FAAS was calibrated using $0,4,12$ and 20 ppm standard solution for $\mathrm{Rh}$ (III) in $1 \mathrm{M} \mathrm{HCl}$. Samples were diluted to measurement limits for precise results. Amount of adsorbed metal ions was calculated from the concentrations in solutions before and after adsorption process. Results were taken from the average of three scans for each sample.

\subsection{Adsorption isotherms}

To simulate the adsorption isotherm, five commonly used models, the Langmuir, Freundlich, Temkin, Dubinin-Radushkevich, and Redlich-Peterson, were selected to explicate metal ion-GAR interactions. These isotherms and their linear forms can be seen in Table I. Although there have been five different linear form of
Langmiur isotherm equations named as Langmuir [7], Competitive Langmuir [8], Lineweaver-Burk [9], EadieHofstee [10-11], Scatchard [13], and log-log [14], only two most commonly used forms, are given in Table I. Lineweaver-Burk linear form [9], is very sensitive to errors, especially in the lower left corner of the chart, it is in a very good agreement with to the experimental data [14]. The $K_{L}$ and $a_{L}$ are the Langmuir isotherm constants and the $K_{L} / a_{L}$ gives the theoretical monolayer saturation capacity, $Q_{0}$.

The essential features of the Langmuir isotherm can be expressed in terms of a dimensionless constant called separation factor $\left(R_{L}\right)$ which is defined by the following equation

$$
R_{L}=\frac{1}{1+a_{L} C_{0}},
$$

where $C_{0}(\mathrm{mg} / \mathrm{l})$ is the initial $\mathrm{Rh}$ (III) concentration and $a_{L}(1 / \mathrm{mg})$ is the Langmuir constant related to the energy of adsorption. In this context, the value of $R_{L}$ indicates the shape of the isotherms to be either unfavorable $\left(R_{L}>1\right)$, linear $\left(R_{L}=1\right)$, favorable $\left(0<R_{L}<1\right)$ or irreversible $\left(R_{L}=0\right)[21]$.

Adsorption isotherms and their linear forms.

TABLE I

\begin{tabular}{|c|c|c|c|c|}
\hline & Isotherm & Linear form & $\mathrm{x} \& \mathrm{y}$ & Slope \& cut-off point \\
\hline $\begin{array}{c}\text { Langmuir } \\
\text { linear }[7,15]\end{array}$ & \multirow{2}{*}{$q_{e}=\frac{K_{L} C_{e}}{1+a_{L} C_{e}}$} & $\frac{C_{e}}{q_{e}}=\frac{1}{K_{L}}+\frac{a_{L} C_{e}}{K_{L}}$ & $\begin{array}{c}x=C_{e}, \\
y=C_{e} / q_{e}\end{array}$ & $\begin{array}{l}\tan \alpha=\frac{a_{L}}{K_{L}}, \\
\text { cutoff }=\frac{1}{K_{I}}\end{array}$ \\
\hline $\begin{array}{c}\text { Lineweaver-Burk } \\
\text { linear [9] }\end{array}$ & & $\frac{1}{q_{e}}=\frac{1}{K_{L}} \frac{1}{C_{e}}+\frac{a_{L}}{K_{L}}$ & $\begin{array}{c}x=1 / C_{e}, \\
y=1 / q_{e}\end{array}$ & $\begin{array}{l}\tan \alpha=\frac{1}{K_{L}}, \\
\text { cutoff }=\frac{a_{L}}{K_{L}}\end{array}$ \\
\hline Freundlich [16] & $q_{e}=K_{f} C_{e}^{1 / n}$ & $\log q_{e}=-\log K_{f}+\frac{1}{n} \log C_{e}$ & $\begin{array}{c}x=\log C_{e} \\
y=\log q_{e}\end{array}$ & $\begin{array}{c}\tan \alpha=\frac{1}{n} \\
\text { cutoff }=-\log K_{f}\end{array}$ \\
\hline Temkin [17] & $\begin{array}{c}q_{e}=\frac{R T}{b} \ln \left(A C_{e}\right) \\
R T / b=B\end{array}$ & $q_{e}=B \ln A+B \ln C_{e}$ & $\begin{array}{c}x=\ln C_{e}, \\
y=q_{e}\end{array}$ & $\begin{array}{c}\tan \alpha=B, \\
\text { cutoff }=B \ln A\end{array}$ \\
\hline$(\mathrm{D}-\mathrm{R})[18,19]$ & $\begin{array}{c}q_{e}=q_{m} e^{-\beta \varepsilon^{2}} \\
\varepsilon=R T\left(1+\frac{1}{C_{e}}\right)\end{array}$ & $\ln q_{e}=\ln q_{m}-\beta \varepsilon^{2}$ & $\begin{array}{c}x=\varepsilon^{2} \\
y=\ln q_{e}\end{array}$ & $\begin{aligned} \tan \alpha & =\beta, \\
\text { cutoff } & =q_{m}\end{aligned}$ \\
\hline$(\mathrm{R}-\mathrm{P})[20]$ & $q_{e}=\frac{A C_{e}}{1+B C_{e}^{g}}$ & $\ln \left(A \frac{C_{e}}{q_{e}}-1\right)=g \ln \left(C_{e}\right)+\ln (B)$ & - & - \\
\hline
\end{tabular}

Freundlich isotherm is widely applied in heterogeneous systems especially for organic compounds or highly interactive species on activated carbon and clays. The Freundlich isotherm is an empirical equation employed to describe heterogeneous systems. Its equation is shown in Table I. In this equation, $K_{f},\left(m g^{1-1 / n} l^{1 / n} g^{-1}\right)$ is the Freundlich constant related to the bonding energy, and $n$, $(\mathrm{g} / \mathrm{l})$ is the heterogeneity factor. The slope $(1 / n)$ ranges between 0 and 1 . It is a measure of adsorption intensity or surface heterogeneity, and it becomes more heterogeneous when its value gets closer to zero. Whereas, a value below unity implies chemisorptions process. Value of $1 / n$ above unity is an indicative of cooperative adsorption [21]. Its linearized and non-linearized equations are listed in Table I.

By ignoring the extremely low and large value of con- centrations, the derivation of the Temkin isotherm assumes that the fall in the heat of sorption is linear rather than logarithmic. Temkin equation is excellent for predicting the gas phase equilibrium. Conversely, complex adsorption systems including the liquid-phase adsorption isotherms are usually not appropriate to be represented. In this equation, $A(1 / \mathrm{mg})$ is the equilibrium binding constant corresponding to the maximum binding energy, $b$ $(\mathrm{J} / \mathrm{mol})$ is Temkin isotherm constant and constant $B$ (dimensionless) is related to the heat of adsorption.

Radushkevich [19] and Dubinin [18] have reported that the characteristic sorption curve is related to the porous structure of the sorbent (Table I). Here constant, $\beta$, $\left(\mathrm{mmol}^{2} / \mathrm{J}^{2}\right)$ is the $\mathrm{D}-\mathrm{R}$ constant related to the mean free energy of sorption per mole of the sorbate, as it is transferred to the surface of the solid from infinite dis- 
tance in the solution and can be correlated using following relationship:

$$
E=1 / \sqrt{2 \beta},
$$

and $q_{m},(\mathrm{mmol} / \mathrm{g})$ is denoted as the single layer capacity. In a deeper explanation, $E$ value indicates the mechanism of the adsorption reaction. When $E<8 \mathrm{~kJ} / \mathrm{mol}$, physical forces may affect the adsorption. If $8<E<16 \mathrm{~kJ} / \mathrm{mol}$, adsorption is governed by ion exchange mechanism, while for the values of $E>18 \mathrm{~kJ} / \mathrm{mol}$, adsorption may be dominated by particle diffusion. The model has often successfully fitted high solute activities and the intermediate range of concentrations data, however it has unsatisfactory asymptotic properties and does not predict the Henry's law at low pressure [21]. Meanwhile, the parameter $\varepsilon$ known as Polanyi potential, can be correlated as

$$
\varepsilon=R T\left(1+\frac{1}{C_{e}}\right),
$$

where $R, T$ and $C_{e}$ represent the gas constant $(8.314 \mathrm{~J} / \mathrm{mol} \mathrm{K})$, absolute temperature $(\mathrm{K})$ and adsorbate equilibrium concentration $(\mathrm{mg} / \mathrm{l})$, respectively.

The Redlich-Peterson isotherm contains three parameters $\left(A(\mathrm{l} / \mathrm{g}), \quad B\left(1 / \mathrm{mg}^{1-1 / A}\right), g\right)$ and incorporates the features of the Langmuir and the Freundlich isotherms [20]. Its equation and linear form can be seen in Table I. Isotherm's unitless constant $g$ has values between $0<g<1$. When $g=1$, adsorption isotherm fits Langmuir isotherm. If $g=0$, isotherm is now fully Freundlich isotherm [21]. Due to having this versatility, it can be applied either to homogeneous or heterogeneous systems.

Because this isotherm contains three constants, it has been demonstrated that the non-linear method is a better way to obtain the isotherm parameters. A trial-and-error procedure, which is applicable to computer operation, was used to compare the best fit of the three isotherms, using the least squares optimization routine to minimize the sum of the squares of the errors, between the experimental data and the isotherms in the solver add-in of the Microsoft's Excel. In addition, the Redlich-Peterson isotherm equation can be resolved by the linear regression method, by transforming it into a linear form.

\subsection{Error analysis}

Linear regression has been one of the most viable tools, defining the best-fitting relationship quantifying the distribution of adsorbates, mathematically analyzing the adsorption systems and verifying the consistency and theoretical assumptions of an isotherm model [21]. Concomitant with the development of computer technology, the progression of the nonlinear isotherm modeling has extensively been facilitated. Contrary to the linearization models, nonlinear regression usually involves the minimization or maximization of error distribution between the experimental data and the predicted isotherm, based on its convergence criteria $[22,23]$. In this study two error functions, the coefficient of determination and nonlinear chi-square test have been used for analyzing the adsorption system.
Coefficient of determination, which represents the percentage of variability in the dependent variable (the variance about the mean) is employed to analyze the fitting degree of isotherm and kinetic models with the experimental data [21]. Coefficient of determination is defined as $[24]$

$$
r^{2}=\frac{\sum\left(q_{e, \text { meas }}-\overline{q_{e, \text { calc }}}\right)^{2}}{\sum\left(q_{e, \text { meas }}-\overline{q_{e, \text { calc }}}\right)^{2}+\left(q_{e, \text { meas }}-q_{e, \text { calc }}\right)^{2}},
$$

where $q_{e, \text { meas }}(\mathrm{mg} / \mathrm{g})$ is the amount of Rh (III) exchanged by the surface of red pine sawdust, obtained from experiment, $q_{e, \text { calc }}$ the amount of Rh (III) obtained by isotherm models and $\overline{q_{e, c a l c}}$ the average of $q_{e, c a l c}(\mathrm{mg} / \mathrm{g})$. Its value may vary from 0 to 1 , and higher values of $r^{2}$, mean that the model is more useful. Essentially, $r^{2}$ tells us how much better we can do in predicting $q_{e, \text { meas }}$ by using the model and computing $q_{e, c a l c}$, than by just using the mean $\overline{q_{e, c a l c}}$ as a predictor.

Nonlinear chi-square test is a statistical tool necessary for the best fit of an adsorption system, obtained by judging the sum of squared differences between the experimental and the calculated data, with each squared difference divided by its corresponding value (calculated from the models). Small $\chi^{2}$ value indicates its similarities while a larger number represents the variation of the experimental data [21].

$$
\chi^{2}=\sum_{i=1}^{n} \frac{\left(q_{e, \text { calc }}-q_{e, \text { meas }}\right)^{2}}{q_{e, \text { meas }}} .
$$

\subsection{Adsorption thermodynamics}

Thermodynamic parameters, such as Gibbs free energy $\left(\Delta \mathrm{G}^{\circ}\right)$, enthalpy change $\left(\Delta \mathrm{H}^{\circ}\right)$ and change in entropy $\left(\Delta \mathrm{S}^{\circ}\right)$ for the adsorption of Rh (III) on red pine sawdust have been determined by using the following equations

$$
\begin{aligned}
& \Delta G^{\circ}=\Delta H^{\circ}-T \Delta S^{\circ}, \\
& \Delta G^{\circ}=-R T \ln \left(K_{L}\right), \\
& K_{L}=\frac{q_{e}}{C_{e}}, \\
& \log \left(\frac{q_{e}}{C_{e}}\right)=\frac{\Delta S^{\circ}}{2.303 R}-\frac{\Delta H^{\circ}}{2.303 R T},
\end{aligned}
$$

where $q_{e}$ is the amount of Rh (III) adsorbed per unit mass of pine cone $(\mathrm{mg} / \mathrm{g}), C_{e}$ is equilibrium concentration $(\mathrm{mg} / \mathrm{l})$ and $T$ is temperature in $\mathrm{K}$ and $R$ is the gas constant $(8.314 \mathrm{~J} / \mathrm{molK})$. Considering the relationship between $\Delta G^{\circ}$ and $K_{L}, \Delta H^{\circ}$ and $\Delta S^{\circ}$ were determined from the slope and intercept of the van't Hoff plots of $\log \left(K_{L}\right)$ versus $1 / T$. Negative values of $\Delta G^{\circ}$ confirm the feasibility of the process and the spontaneous nature of the adsorption. In general, the $\Delta H^{\circ}$ value of physisorption is smaller than $40 \mathrm{~kJ} / \mathrm{mol}$. The positive value of $\Delta H^{\circ}$ is indicating that the adsorption reaction was endothermic [25]. The negative entropy change $\left(\Delta S^{\circ}\right)$ for the process was caused by the decrease in degree of freedom of the adsorbed species [26]. 


\section{Results and discussion}

PGMs can be present in the form of chloro-complexes. These forms are having very complicated solution chemistry. The species' composition is dependent on factors such as chloride concentration, $\mathrm{pH}$, ionic strength, temperature, and the age of the solution. The formation of metal complexes by PGMs is related to the solution composition. This in turn may affect the adsorption mechanism involved, i.e. chelation rather than ion exchange, and the affinity of the metal species for sorption sites on the adsorbents. Solution chemistry of PGMs is generally very different to that of base metals. When comparing to other PGMs, rhodium ions adsorption acidity is the strongest one. This is another difficulty for adsorbents, they can easily decompose or dissolve. In order to avoid this situation, synthesized biopolymer must have a good acid resistance.

\subsection{Effect of acidity}

The $\mathrm{pH}$ of the aqueous solution is one of the important controlling parameters in the sorption process of PGMs. The effect of initial $\mathrm{pH}$ was studied at the $\mathrm{pH}$ ranges of $0-4.5$ in 0.5 steps and results are shown in Fig. 1. The amounts of adsorbed Rh (III) have increased from 8.2 to $0.54 \mathrm{mg} / \mathrm{g}$, with the decrease of $\mathrm{pH}$ from 4.5 to 0 .

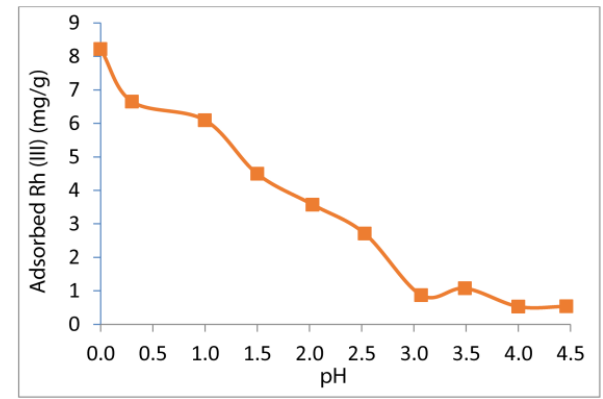

Fig. 1. Influence of $\mathrm{pH}$ on $\mathrm{Rh}$ (III) adsorption $\left(C_{0}=\right.$ $60 \mathrm{mg} / \mathrm{l}, 0.2 \mathrm{~g} \mathrm{GAR}, 293 \mathrm{~K}, \mathrm{pCl}=3, V=50 \mathrm{ml}, t=$ $60 \mathrm{~min})$.

\subsection{Effect of chlorine concentration}

In order to understand the effect of $\mathrm{Cl}^{-}$concentration on the adsorption of Rh (III) onto GAR particles, experiments were carried out in batch systems with different stirring rates, changing from $10^{-3}-1 \mathrm{M} \mathrm{Cl}^{-}$. Obtained results are shown in Fig. 2. As can be seen, adsorption capacity is higher at higher $\mathrm{Cl}^{-}$concentration. This shows that chlorine ions have a positive effect on the $\mathrm{Rh}$ (III) adsorption. In this conditions $(1 \mathrm{M} \mathrm{HCl})$, $\mathrm{Rh}$ (III) species which are formed in $\left[\mathrm{RhCl}_{5} \mathrm{H}_{2} \mathrm{O}\right]^{2-}$ and $\left[\mathrm{RhCl}_{2}\left(\mathrm{H}_{2} \mathrm{O}\right)_{4}\right]^{-}$are expected to occur more often than the positive charged and natural Rh (III) species [27]. It can be observed that the increase in $\left[\mathrm{Cl}^{-}\right]$leads to an increase in Rh (III) adsorption capacity, from $14.11 \mathrm{mg} \mathrm{g}^{-1}$

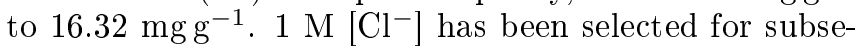
quent experiments.

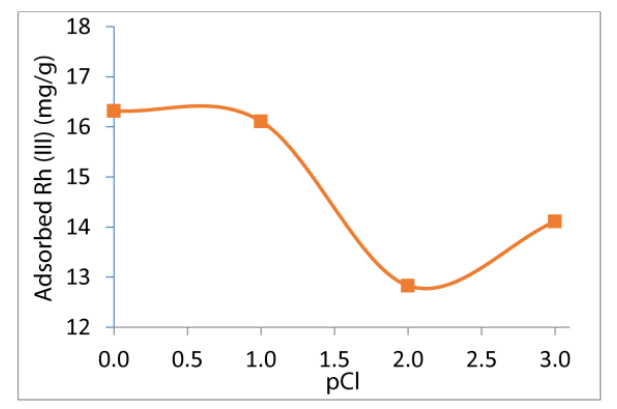

Fig. 2. Influence of $\mathrm{Cl}^{-}$concentration on $\mathrm{Rh}$ (III) adsorption $\left(C_{0}=50 \mathrm{mg} / 1,0.2 \mathrm{~g}\right.$ GAR, $293 \mathrm{~K}, 1 \mathrm{M} \mathrm{HCl}$, $V=50 \mathrm{ml}, t=60 \mathrm{~min})$.

\subsection{Effect of GAR mass}

The effect of the adsorbent dosage on adsorptions of $\mathrm{Rh}$ (III) on the surface of GAR particles is shown in Fig. 3. GAR mass was varied between $0.025-0.15 \mathrm{~g}$ with $0.025 \mathrm{~g}$ steps and equilibrated for $60 \mathrm{~min}$. It can be seen from Fig. 3 that the adsorption increases with increase in GAR mass. The efficiency was $4.894 \%$ at the adsorbent concentration of $0.5 \mathrm{~g} / \mathrm{l}$, while it varied from $4.894 \%$ to $22.19 \%$ at adsorbent concentrations of $0.5-3 \mathrm{~g} / \mathrm{l}$ for $\mathrm{Rh}$ (III), respectively. Although adsorbent dosage has increased 5 times, the removal, greater than $0.5 \mathrm{~g} / \mathrm{l}$, has increased by up to about 400 percent. With the increase of the GAR dose, the amount of adsorbed Rh (III) increases, but the adsorption density decreases. This is due to the increase of the number of available adsorption sites with the increase of the adsorbent dose. In addition, aggregation of particles may have a reductive impact on the adsorption density. This situation will reduce surface area of adsorbents and will increase the diffusion path length. Thus, the equilibrium concentration of GAR particles is considered to be $0.1 \mathrm{~g}$.

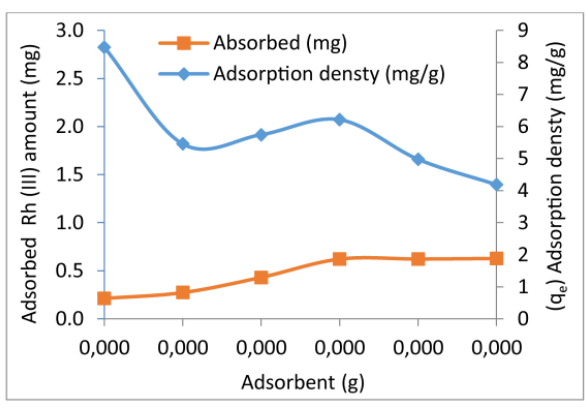

Fig. 3. The effects of adsorbent dosage on $\mathrm{Rh}$ (III) adsorption $\left(1 \mathrm{M} \mathrm{HCl}, C_{0}=118.4 \mathrm{mg} / 1,293 \mathrm{~K}, V=50 \mathrm{ml}\right.$, $t=60 \mathrm{~min})$.

\subsection{Effect of contact time and initial $R h$ (III) concentration}

The preliminary experiments showed that the adsorption of $\mathrm{Rh}$ (III) is fast at the initial stages and becomes slower near the equilibrium. Figure 4 presents the plots of $\mathrm{Rh}$ (III) removal versus contact time for GAR particles at initial concentrations between 16.54 and $88.80 \mathrm{mg} / \mathrm{l}$ 
at $298 \mathrm{~K}$ with a contact time of $150 \mathrm{~min}$. The rate of $\mathrm{Rh}$ (III) removal is very rapid for first 20 minutes and thereafter the plot flattens. It is revealed that there was no considerable change in adsorption of $\mathrm{Rh}$ (III) after $90 \mathrm{~min}$ for varied initial concentrations. The equilibrium times are independent of initial $\mathrm{Rh}$ (III) concentration. With the increase in the initial $\mathrm{Rh}$ (III) concentration, the efficiency increases. This phenomenon can be explained by the high adsorption capacity of the GAR particles.

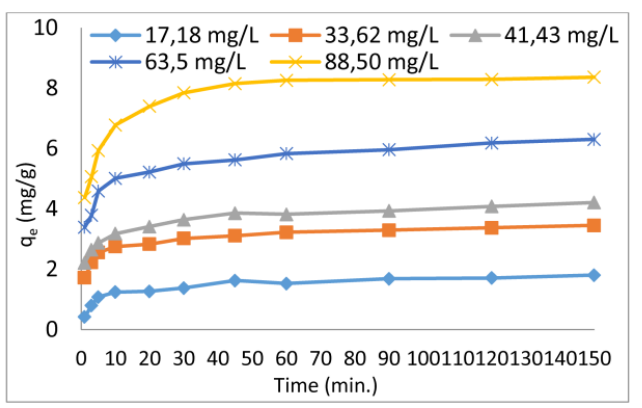

Fig. 4. The effects of contact time and initial Rh (III) concentration on adsorption $(1 \mathrm{~g}$ GAR, $1 \mathrm{M} \mathrm{HCl}, 293 \mathrm{~K}$, $V=1000 \mathrm{ml}$ ).

\section{Adsorption isotherms}

Four most used isotherms are selected in this study, which are the Langmuir, Freundlich, Tempkin, DubininRadushkevich, and Redlich-Peterson isotherms. A comparison of the linear and the nonlinear solutions of Langmuir isotherm was carried out first. Then, Freundlich, Tempkin, Dubinin-Radushkevich, and Redlich-Peterson, have been applied to the experiment of $\mathrm{Rh}$ (III) sorption on GAR particles. Here, at linear forms, Pearson's correlation coefficient $\left(r^{2}\right)$ error function, and at nonlinear solutions, Pearson's Chi-square $\left(\chi^{2}\right)$ error function were taken into consideration. Then for others, the error function was calculated. In addition, in the nonlinear Langmuir solution, the predicted values where generated from a model different than the linear regression. $r^{2}$ value can be calculated between the measured $q_{e}$ and modeled $q_{e}$ data values. In this case, the value is not directly a measure of how good the modeled values are, but rather a measure of how good a predictor might be constructed from the modeled values. This usage is specifically the definition of the term "coefficient of determination": the square of the correlation between two variables.

Linear regression has been one of the most acceptable tools defining the best-fitting relationship, quantifying the distribution of adsorbates, mathematically analyzing the adsorption systems and verifying the consistency and theoretical assumptions of an isotherm model. Contrary to the linearization models, nonlinear regression usually involves the minimization or maximization of error distribution (between the experimental data and the predicted isotherm) based on its convergence criteria. However, there is an opinion about nonlinear regression being also not statistically correct. This opinion is based on experimental errors in both the dependent and the independent variables in the isotherm equations [28]. In this case, $r^{2}$ values for both linear forms of Langmuir isotherm were significantly different as is summarized in Table II. When using just the linear forms of Langmuir isotherms for comparison, Lineweaver-Burk linear form was more suitable for the experimental data than the Langmuir linear form. In contrary to this, when considering $\chi^{2}$ values, linear form of Langmuir was most suitable among the two linearized forms. Even though the most suitable isotherm for the dataset was LineweaverBurk form, the differences between the two linear forms of Langmuir isotherms are significantly in agreement with experimental results. Each linear equation has different axial settings individually, so that would alter the result of a linear regression and influence the determination process. For this reason, it is not appropriate to use $r^{2}$ of linear regression analysis for comparison of the betterfitting of Freundlich, Tempkin, Dubinin-Radushkevich, and both linear Langmuir isotherms. $\chi^{2}$ (Pearson's Chisquare) error function analysis could be a better method.

Langmuir isotherm constants for Rh (III) adsorption onto GAR particles.

TABLE II

\begin{tabular}{|c|c|c|c|c|c|}
\hline \multicolumn{3}{|c|}{\begin{tabular}{c|c|c|}
$K_{L}[\mathrm{l} / \mathrm{g}]$ & $a_{L}[\mathrm{l} / \mathrm{mg}]$ & $Q_{\max }[\mathrm{mg} / \mathrm{g}$
\end{tabular}} & $R_{L}$ & $r^{2}$ & $\chi^{2}$ \\
\hline \multicolumn{6}{|c|}{ Lineweaver-Burk linear } \\
\hline 0.1202 & 0.0017 & 69.43 & $0.867-0.971$ & 0.99997 & 0.007 \\
\hline \multicolumn{6}{|c|}{ Langmuir linear } \\
\hline 0.1210 & 0.0019 & 63.63 & $0.856-0.968$ & 0.98055 & 0.006 \\
\hline \multicolumn{6}{|c|}{ Nonlinear regression } \\
\hline 0.1223 & 0.0021 & 58.11 & $0.843-0.965$ & 0.99784 & 0.008 \\
\hline \multicolumn{4}{|c|}{ Freundlich: $K_{f}=7.053[\mathrm{l} / \mathrm{g}], n=1.070$} & 0.9994 & 0.015 \\
\hline \multicolumn{4}{|c|}{ Tempkin: $A=0.089[\mathrm{l} / \mathrm{g}], B=3.952[\mathrm{~J} / \mathrm{mol}]$} & 0.9554 & 0.1822 \\
\hline \multicolumn{4}{|c|}{$\begin{array}{l}\text { Dubinin-Radushkevich: } \beta=0.600[\mathrm{mmol} / \mathrm{J}]^{2} \\
q_{m}=6.519[\mathrm{mmol} / \mathrm{g}], E=0.913[\mathrm{~kJ} / \mathrm{mol}]\end{array}$} & 0.8471 & 0.2343 \\
\hline \multicolumn{4}{|c|}{$\begin{array}{l}\text { Redlich-Peterson: } K=0.120[\mathrm{l} / \mathrm{g}] \\
a=0.002[\mathrm{l} / \mathrm{mg}], \beta=1.0000\end{array}$} & $0.9978^{*}$ & 0.007 \\
\hline
\end{tabular}

Chi-square distribution value the DubininRadushkevich and Tempkin isotherm was significantly higher. Based on the $\chi^{2}$ values, as indicated in Table II, one can say that Lineweaver-Burk form is the best reliable method for solution of the Langmuir isotherm. Beyond that, the best fitting isotherm of the five studied isotherms are Redlich-Peterson isotherm for Rh (III) adsorption. Coefficient of determination $\left(r^{2}\right)$ showed that the Langmuir nonlinear method is the most appropriate one (having $r^{2}$ value of 0.99997 ). According to Langmuir Lineweaver-Burk form, monolayer saturation capacity of $\mathrm{Rh}$ (III) on the GAR particles was determined as $69.43 \mathrm{mg} / \mathrm{g}$.

The calculated $R_{L}$ values at different initial rhodium concentrations are shown in Fig. 5. Dimensionless constant, $R_{L}$, indicates the shape of the isotherms to be either unfavorable $\left(R_{L}>1\right)$, linear $\left(R_{L}=1\right)$, favorable $\left(0<R_{L}<1\right)$ or irreversible $\left(R_{L}=0\right)$. It is observed that, $R_{L}$ values for $\mathrm{Rh}$ (III) ions were determined be- 
tween 0.871-0.971. This indicated that adsorption was more favorable for the higher initial Rh (III) concentrations than for the lower ones. Freundlich isotherm is widely applied in heterogeneous systems, especially for organic compounds or highly interactive species on activated carbon and molecular sieves. The slope $(1 / n)$, ranging between 0 and 1 , is a measure of adsorption intensity or surface heterogeneity, and it becomes more homogeneous when its value gets closer to one. Slope of $\mathrm{Rh}$ (III) was determined as 0.9346 . These results are further evidence of the surface homogeneity. Tempkin isotherm is showing less agreement with the experimental data, $\chi^{2}$ value is 0.1822 for $\mathrm{Rh}$ (III). Hence, it can be considered as indication of fact that the surface is not heterogeneous. Here the relatively high (Table II) Langmuir's $\mathrm{R}_{L}$ values at initial concentrations, have caused relatively low $\chi^{2}$ values for adsorption systems.

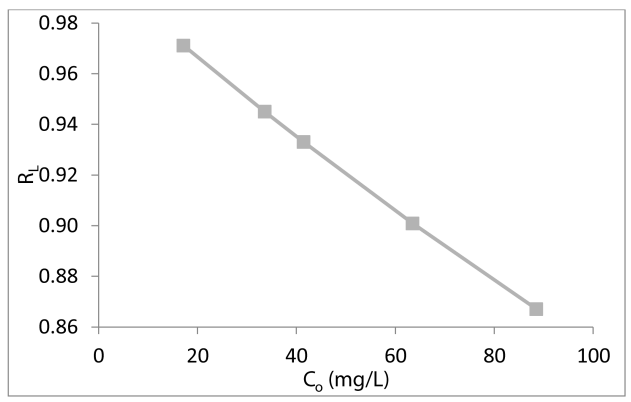

Fig. 5. Plots of separation factor versus initial Rh (III) concentrations.

Dubinin-Radushkevich isotherm constant, $\beta$ $\left(\mathrm{mmol}^{2} / \mathrm{J}^{2}\right)$, has been used to calculate the mean free energy $(E)$ of sorption per mole of the adsorbate. $E$ value was calculated as 0.913 for Rh (III). Because $E$ is in the range of $8<E<16 \mathrm{~kJ} / \mathrm{mol}$, the adsorption is governed by ion exchange mechanism [28]. Using Langmuir's $Q_{\max }(\mathrm{mg} / \mathrm{g})$ and Dubinin-Radushkevich's $q_{m}$ $(\mathrm{mmol} / \mathrm{g})$ values, unknown molecular weight of Rh (III) can be calculated approximately. This is because, especially for the Dubinin-Radushkevich isotherm, the compliance of isotherms to experimental data is low. The Redlich-Peterson isotherm parameters $K(\mathrm{l} / \mathrm{g}), a$ $\left(1 / \mathrm{mg}^{1-1 / A}\right)$, and $\beta$ can be seen in Table II. Because the unitless constant $\beta$ has value of 0.6 for $\mathrm{Rh}$ (III), adsorption isotherm fits the Langmuir isotherm. A comparison is also made between the experimental data and worked isotherms plotted in Fig. 6. As can be seen from Table II, the Langmuir, Freundlich, and RedlichPeterson isotherms equations show enough compliance to the experimental results. Despite the fact that Dubinin-Radushkevich isotherm represents adsorption systems at low concentrations, the Tempkin's isotherm is generally in more agreement with experimental data than Dubinin-Radushkevich isotherm. Based on Fig. 6 , one can say that the Lineweaver-Burk Langmuir form generates a satisfactory fit to the experimental data at all data points.

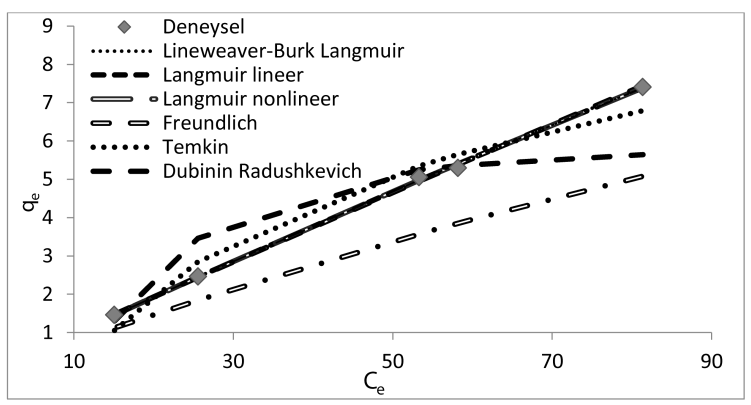

Fig. 6. The measured and the modeled non-linear time profiles for adsorption of the Rh (III) onto GAR particles $(1 \mathrm{~g}$ GAR, $1 \mathrm{M} \mathrm{HCl}, 293 \mathrm{~K}, V=1 \mathrm{l})$.

\section{Effect of temperature on adsorption}

In order to understand the effect of temperature on adsorption of Rh (III) ions on GAR particles, experiments at 293, 303, 313, 323, 333 and $343 \mathrm{~K}$ temperatures were studied, and the results are shown in Fig. 7. Results indicate that amount of adsorbed Rh (III) ions increases with the increase of temperature. For example, for initial Rh (III) concentration of $78.76 \mathrm{mg} / 1$ (in $50 \mathrm{ml}$ volumes), when initial solution temperature was increased from 298 to $353 \mathrm{~K}$, the amount of $\mathrm{Rh}$ (III) ions adsorbed per unit weight of GAR increased from 2.54 to $7.25 \mathrm{mg} / \mathrm{g}$. The increase in the adsorption capacity at increased temperature indicates the endothermic nature of the adsorption process of Rh (III) onto GAR.

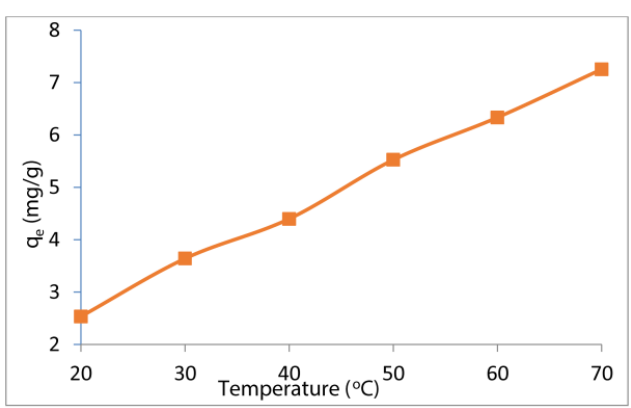

Fig. 7. Effect of temperature on the adsorption of Rh (III) ions $\left(C_{0}=78.76 \mathrm{mg} / 1,0.2 \mathrm{~g}\right.$ GAR, $1 \mathrm{M} \mathrm{HCl}$, $V=50 \mathrm{ml}, 60 \mathrm{~min})$.

\section{Determination of thermodynamic parameters}

The plot of $\ln K_{L}$ against $1 / T$ is linear, thus $\Delta H^{\circ}$ and $\Delta S^{\circ}$ were calculated from the slope and intercept of the line, respectively. The slope of the van't Hoff plot is equal to $-\Delta H^{\circ} / R$, and its interception is equal to $\Delta S^{\circ} / R$. The van't Hoff plot for the adsorption of Rh (III) onto GAR particles is given in Fig. 8.

The obtained thermodynamic parameters are given in Table III. As shown in the table, the negative values of $\Delta G^{\circ}$ at different temperatures indicate the spontaneous nature of the adsorption process.

The positive value of $\Delta H^{\circ}$ suggests the endothermic nature of adsorption system. Generally when $\Delta H^{\circ}$ value 


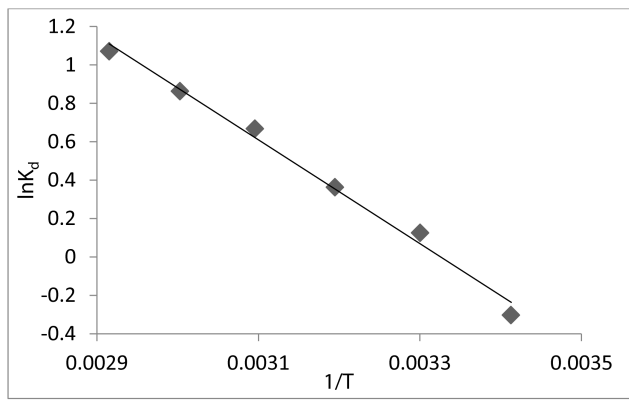

Fig. 8. Van't Hoff graphic of the Rh (III)-GAR adsorption system.

Thermodynamic parameters for the adsorption of Rh (III) ions onto GAR particles.

\begin{tabular}{c|c|c|c|c|c|c|c}
\hline \hline$\Delta H^{\circ}$ & $\Delta S^{\circ}$ & \multicolumn{5}{|c}{$\Delta G^{\circ}[\mathrm{kJ} / \mathrm{mol} \mathrm{K}]$} \\
\cline { 3 - 7 }$[\mathrm{kJ} / \mathrm{mol} \mathrm{K}]$ & {$[\mathrm{J} / \mathrm{mol} \mathrm{K}]$} & $293 \mathrm{~K}$ & $303 \mathrm{~K}$ & $313 \mathrm{~K}$ & $323 \mathrm{~K}$ & 333 & $343 \mathrm{~K}$ \\
\hline 22.50 & 74.83 & -0.036 & -0.319 & -0.947 & -1.795 & -2.391 & -3.053
\end{tabular}

is smaller than $40 \mathrm{~kJ} /(\mathrm{mol} \mathrm{K})$, the interaction is assumed as weak interaction or physisorption [28]. Based on this study $\Delta H^{\circ}$ values were determined as $22.50 \mathrm{~kJ} /(\mathrm{mol} \mathrm{K})$ for $\mathrm{Rh}$ (III). This suggests that the adsorption of Rh (III) ions onto GAR particles is driven by the physisorption process. The positive value of $\Delta S^{\circ}$ suggests the increase of randomness at the solid/solution interface during the adsorption.

\section{Desorption of Rh (III) ions}

Desorption of Rh (III) ions from the surface of GAR particles was rapid and equilibrium was achieved within 45 minutes. The adsorption experiments were performed at optimum conditions and then recovery experiments were conducted. As shown in Table IV, different elation solution were selected in order to determine the most efficient one. 100 percent desorbtion was achieved with all stripping solutions.

TABLE IV

The recovery efficiency of $\mathrm{Rh}$ (III) ions with different eluent.

\begin{tabular}{c|c}
\hline \hline Stripping solution & Recovery (\%) \\
\hline $1 \mathrm{M} \mathrm{HNO}_{3}+0.1 \mathrm{M} \mathrm{NaClO}_{3}$ & 100 \\
$1 \mathrm{M} \mathrm{HNO}_{3}+0.1 \mathrm{M} \mathrm{NaClO}$ & 100 \\
$1 \mathrm{M} \mathrm{HNO}_{3}+0.1 \mathrm{M} \mathrm{H}_{2} 0_{2}$ & 100
\end{tabular}

\section{Conclusions}

The adsorption of Rh (III) ions has been studied with GAR resin particles. The acidity of solutions and the adsorption temperature were found to affect the adsorption of Rh (III) ions. It was found that GAR had a monolayer of $\mathrm{Rh}$ (III) and experimental adsorption capacities were found to be 69.43 and $8.36 \mathrm{mg}$ Rh (III)/g GAR. Here, the adsorption data fitted better the Langmuir isotherm then other four studied isotherms. The calculated Gibbs free energies $\left(\Delta G^{\circ}\right)$ were changing from $-0.0036 \mathrm{~kJ} / \mathrm{mol}$ to $3.053 \mathrm{~kJ} / \mathrm{mol}$ at $293 \mathrm{~K}$ an $343 \mathrm{~K}$, respectively. These $\Delta G^{\circ}$ values show that a spontaneous adsorption process occurs at room temperature. The enthalpy change $\left(\Delta H^{\circ}\right)$, and the entropy change $\left(\Delta S^{\circ}\right)$ were $22.50 \mathrm{~kJ} / \mathrm{mol}$ and $74.83 \mathrm{~J} / \mathrm{mol}$, respectively. Adsorbed $\mathrm{Rh}$ (III) ions can be desorbed with each three stripping solutions with $100 \%$ efficiency.

\section{References}

[1] M. Goto, H. Kasaini, S. Furusaki, Sep. Sci. Technol. 35, 1307 (2000).

[2] M.S. Alam, K. Inoue, K. Yoshizuka, H. Ishibashi, Sep. Sci. Technol. 33, 655 (1998).

[3] M. Can, E. Bulut, A. Örnek, M. Özacar, Chem. Eng. J. 221, 146 (2013).

[4] M. Can, E. Bulut, M. Özacar, J. Chem. Eng. Data 57, 2710 (2012).

[5] M. Can, Res. J. Chem. Environ. 17, 1 (2013).

[6] M. Can, E. Bulut, M. Özacar, Ind. Eng. Chem. Res. 51, 6052 (2012).

[7] I. Langmuir, J. Am. Chem. Soc. 40, 1361 (1918).

[8] O. Altın, H.Ö. Özbelge, T. Doğu, J. Coll. Interf. Sci. 198, 130 (1998).

[9] H. Lineweaver, D. Burk, J. Am. Chem. Soc. 56, 658 (1934).

[10] G.S. Eadie, J. Biol. Chem. 146, 85 (1942).

[11] G.S. Eadie, Science 116, 329 (1952).

[12] B.H.J. Hofstee, Pure and Appl. Chem. 51, 1537 (1979).

[13] G. Scatchard, Ann. N.Y. Acad. Sci. 51, 660 (1949).

[14] M.I. El-Khaiary, J. Hazard. Mater. 158, 73 (2008).

[15] I. Langmuir, J. Am. Chem. Soc. 38, 2221 (1916).

[16] H.M.F. Freundlich, Zh. Fiz. Khim.(Russian Journal Of Physical Chemistry) 57, 385 (1906).

[17] M.I. Temkin, Zh. Fiz. Khim.(Russian Journal Of Physical Chemistry) 15, 296 (1941).

[18] M.M. Dubinin, Zh. Fiz. Khim.(Russian Journal Of Physical Chemistry) 39, 1305 (1965).

[19] L.V. Radushkevich, Zh. Fiz. Khim.(Russian Journal Of Physical Chemistry) 23, 1410 (1949).

[20] O. Redlich, DL. Peterson, J Phys. Chem. A 63, 1024 (1959).

[21] K.Y. Foo, B.H. Hameed, Chem. Eng. J. 156, 2 (2010).

[22] K.V. Kumar, S. Sivanesan, J. Hazard. Mater. 123, 288 (2005).

[23] M. Can, Res. J. Chem. Environ. 17, 117 (2013).

[24] Y.S. Ho, Water Res. 40, 119 (2006).

[25] Y. Yao, F. Xu, M. Chen, Z. Xu, Z. Zhu, Biores. Technol. 101, 3040 (2010).

[26] Y.A. Aydın, N.D. Aksoy, Chem. Eng. J. 151, 188 (2009).

[27] D. Pletcher, R.I. Urbina, J. Electroanal. Chem. 421 , 137 (1997).

[28] M. Can, Desalin. Water Treat. (2015). 